\title{
The effect of electromagnetic flux density on the ionization and the combustion of fuel (An economy design project)
}

\author{
${ }^{1}$ Engr. Okoronkwo C. A , ${ }^{2}$ Engr. Dr. Nwachukwu, C.C, ${ }^{3}$ Engr. Dr. Ngozi -Olehi L.C and \\ ${ }^{4}$ Engr. Igbokwe, J.O
}

${ }^{1}$ Department Of Mechanical Engineering, Federal University of Technology, Owerri, Imo State. E-MAIL: Chukwunenye jireh@yahoo.com Phone: 08035448120

${ }^{2}$ Lecturer, Department of Project Management Technology, Federal University of Technology, Owerri, Imo State. GSM; 08033289740, E-Mail nedumchisma@yahoo.com

${ }^{3}$ Deparment of Chemistry, Alvan Ikoku Federal College Of Education ,Owerri

E-Mail: mrs ngoziolehi@yahoo.com.ca, 08030886970

${ }^{4}$ Department of Mechanical Engineering Federal University of Technology, Owerri, Imo State. 08037757484

\begin{abstract}
A comprehensive experimental study on the effect of electromagnetic field on the ionization and combustion of fuel in an internal combustion engine is presented. The major aim is for the user economy and environmental friendly especially as it may affect climate change. The experimental set up consist a HGA 200 computerized exhaust gas analyzer, one cylinder 4 stroke engine, a copper wire wound round a hollow cylindrical rod which is connected to a DC $12 \mathrm{~V}$ battery. The exhaust product was channeled to the HGA 200 for proper analysis of the exhaust constituent . The set up was allowed to run for one hour without the electromagnetic device to serve as a base line for comparison. Series of test runs were conducted using the device along the fuel line of the engine. Results obtained during the test, gave a $50 \%$ reduction in the hydrocarbon constituent of the exhaust product in PPM and $35 \%$ reduction in the carbon monoxide. These results clearly indicate that the introduction of an electromagnetic field within the fuel line of an I.C engine enhances the combustion process thereby economizing fuel consumption and reducing gas emission making it environmental friendly engine. They study suggest that the materials for the inlet manifold and the top cylinder of the engine be made from a magnetic material. This will create a permanent magnet around the combustion chamber for proper mixing and the burning of the fuel.
\end{abstract}

Keywords: ionization, exhaust gas analyzer, emission control, economic design project etc.

\section{INTRODUCTION}

For many years, researchers tried to design which a combustion system has low air pollution through completely combustion hydrocarbon. Various techniques, such as air-fuel mixing, ignition, temperature controlling combustion chamber and catalyst that have been developed, are not able to completely resolve the problems yet [1]. Low efficiency of combustion heat, unburned fuel and air pollution (like CO, NOx, SOx and shoot) are still problem now. It is caused by which some aspects are not explored yet, they are

The concept of exposing fuel molecules to magnetic field dates back to J.D Van-der Waals and his experiments in the field. It is well know that hydrocarbon have long branched geometric chains of carbon atom, which have tendency to fold over unto themselves and on adjoining molecules due to intermolecular electromagnetic attraction existing between them. Fuel molecules have tendency to interlock with other compounds temporally forming pseudo-compounds, subjecting these pseudocompound to magnetic field of appropriate strength and direction tends to un-cluster the molecular grouping resulting in a reduction of fluid viscosity at the macroscopic levels, hence proper mixing, and the reduction in the delay period of combustion ensues.

Van der Waals applied a magnetic field to fuel molecules and found out that the viscosity of the fuel decreases with the application of the field and consequently an increase in the flow rate of the fuel. This is because all substances according to faraday 
are affected by a magnetic field though; in most cases, this influence may be insignificant. Fuel molecules subjected to external magnetic field, are usually excited, which in turn causes mole reorientation in order to accommodate the applied external magnetic field [2]. The above phenomenon is attributed to the fact that on the molecular level, a spinning electron subjected to a precise amount of electromagnetic energy absorbs that energy and spin-flip into an aligned state. The present study became imperative because of the inherent pollution to the environment due incomplete combustion of fuel. In this paper, the authors sought to investigate the effect of electromagnetic field on the combustion process.

\section{Electromagnetic field and emission control:} Vehicles contribute to the pollution of the environment from several sources such as the unburned $\mathrm{HC}$ coming from the fuel tank, the exhaust from the product of combustion. This produces $\mathrm{CO}$, $\mathrm{CO}_{2}, \mathrm{NO}_{\mathrm{X}}$ and particulates into the atmosphere. When these pollutants are in place, an atmospheric phenomenon called smog is created by the action of sunlight on hydrocarbon $(\mathrm{HC})$ in the atmosphere, and the main source of $\mathrm{HC}$ is the exhaust gases of motor vehicles, the rapid increase in traffic causes the increase in the percentage of smog. Several approaches has been adopted to control exhaust emission to a manageable extent, some of these includes, increasing the air /fuel ratio, and recirculating part of the exhaust gas through the cylinder, reduces $\mathrm{CO}$ and $\mathrm{HC}$ output ,controls NOx but does not improve the fuel consumption efficiency.

Nevertheless, the most contributing factor for the discharge of $\mathrm{HC}, \mathrm{CO}$ and NOx to the atmosphere is the excessive introduction of clustered fuel molecules into the combustion chamber within a short period. The above, leads to a situation where the fuel particle passes through the combustion chamber un-burnt, thereby releasing the $\mathrm{CO}, \mathrm{HC}$, and NOx constituent of the exhaust product into the atmosphere. Efforts to reduce this abnormality lead to the introduction of canister and catalytic converters along the exhaust line to reduce exhaust pollution. For newer vehicles, problems of exhaust pollution has reduced to the lowest minimum, but for older vehicles this problem still exist especially in the developing countries[3].

Several US patents have shown that magnetic field can improve complete combustion, but most of these claims are intuitively based without any strong experimental data to support their validity. The present work aims to provide experimental data to prove that magnetic field affects the fuel combustion of internal combustion engines. As cited in numerous scientific reports the principle causes of Global Warming are worldwide increases in carbon dioxide (CO2), nitrous oxide (N2O), methane, water vapor, CFCs, and ozone. Highway vehicles are estimated to constitute $77 \%$ of the total Green House Gas (GHG) emissions for the United States by mobile sources and an equal percentage can be extrapolated to other regions using this form of emissions reduction. It is interesting to note, according to Hal Campbell[6] ,that the from 1990 to 2001, GHG (Green House Gas) for the United States, as a result of mobile sources of related emissions, increased by $24.3 \%$, from 1,172 to $1,456(\mathrm{Gg})$. This increases in GHG emissions comes despite the fact that from 1990 to 2001, CO emissions from mobile combustion in the U.S. have decreased from 98,328 to $66,857(\mathrm{Gg})$, and NOx emissions have declined by 5.746 to 3.942 (Gg). Even with these reductions, Green House Gas emissions have risen by 24.3 percent. A strong correlation between the use of catalytic converters as a source of emissions control as measured by the mean number of vehicles equipped with such technology, as compared to increases in GHG is evident. So to, is the relationship that exists in elevating GHG emissions and mean global temperatures. The use of catalytic converters in passenger cars, light trucks, and heavy-duty trucks since 1973 to present times has seen a complete reversal, from practically no such devices being used in 1973 to nearly all vehicles manufactured being equipped with these devices today. Clearly the explanation for the global increase in GHG emissions is multivariate in nature and due (partly) to the aggregate effect of a variety of variables that include (a) an increase in vehicle miles driven annually, (b) an increase in the number of vehicles produced annually, but also and perhaps most significantly to (c) the percentage of vehicles now in use equipped with catalytic converters. [4]

To further mitigate the effect of global warming caused by the use of catalytic converters, it has been discovered that treatment of fuels by short pulse magnetic field, prior to combustion, can affect changes in the molecular structure of crude oil and derivative fuels, thereby resulting in a decrease in surface tension and favorable alteration in viscosity levels. Nelson Saksono [5], in his study on the influence of Magnetization on the thermal efficiency of kerosene pressurized stove, discovered that, 
magnetization can increase the thermal efficiency of kerosene pressurized stove. Subsequently, the process of exposing fuel to electric or magnetic fields subsequent to carburetion or fuel injection and just prior to combustion, can enhance the combustion process thereby increasing the exposure of fuel molecules so that oxygen molecules can bond with more individual fuel molecules. This enhanced level of combustion, results in more fuel molecules, per cluster, and subsequently lessening the amount of unburned fuel from the engine. This enhanced combustion process also decreases the amount of unburned fuel waste requiring incineration by the catalytic converter. Such an increase in engine effectiveness also results in improved gas mileage, because more particles of fuel (per cluster) are being combusted, thereby requiring fewer clusters of fuel by the engine, per mile of travel. Since $\mathrm{CO} 2$ is a natural by-product of the incineration of $\mathrm{CO}$, the only effective way to reduce the production of this GHG is to incinerate less CO. Additionally, since $\mathrm{N}_{2} \mathrm{O}$ is a natural by-product of incineration of $\mathrm{NO}_{x}$, the only way to reduce the production of this GHG is also to incinerate less $\mathrm{NO}_{x} \cdot[6]$

Magnetic and electric treatment of fuels prior to combustion can serve to achieve this objective and provide a practical method by which to lower the volume of unburned gases requiring incineration by catalytic converter.

\section{MATERIALS AND METHODS}

The experimental set up is consist of digital exhaust gas analyzer, a one cylinder 4 stroke Imex 160 engine, battery, stop watch etc. These components are connected together see fig 1 . At the beginning, 4 litres of fuel was fed into the engine tank and the engine was allowed to run for one hour. The essence of using a measured amount of fuel is to establish an assessment criterion, which will serve as a baseline for comparison with and without the electromagnetic device. After the first one hour, the exhaust tail pipe was connected to the gas analyzer with a transparent flexible hose. The exhaust constituent measured includes the $\mathrm{HC}, \mathrm{CO}$ and $\mathrm{CO} 2$. The analyzer presents the $\mathrm{HC}$ constituent in Parts per Million (PPM).The $\mathrm{CO}$ was measured in percentage composition. The readings were taken at 5 minutes intervals. Two sets of experiments were carried out one with the device and the other without the device.



Fig 1. Experimental set up 
Am. J. Sci. Ind. Res., 2010, 1(3): 527-531

\section{RESULTS AND DISCUSSION}

The experimental results for the present study are presented in fig 2-5 (see appendix). Fig 2 shows the $\mathrm{HC}$ constituents measured by the exhaust gas analyzer without the magnetic device. This figure serves as a baseline for comparison between the introduction of the magnet device, and when it is not in use. The reason for the present study is to evaluate the appropriateness of the device to reduce tailpipe emission. The evaluation of the difference between the data collected will serve as a yardstick for comparison.

Fig 3 is the emission of $\mathrm{CO}$ with the device in place.

Fig 4 is the comparison between the $\mathrm{HC}$ emitted with and without the device; a closer look shows at all time that the emission without the device is higher than with the device. This is a clear indication that magnetic field effects the combustion of fuel. Similarly, in fig 5, the variation between the $\mathrm{CO}$ emitted with and without the device, shows a similar trend like the $\mathrm{HC}$ constituent in fig 4. By using the mean deviation analysis, a $50 \%$ reduction in the $\mathrm{HC}$ was obtained, while $35 \%$ reduction was obtained for the $\mathrm{CO}$ constituent.



Fig 2 showing the $\mathrm{HC}$ constituent without the device

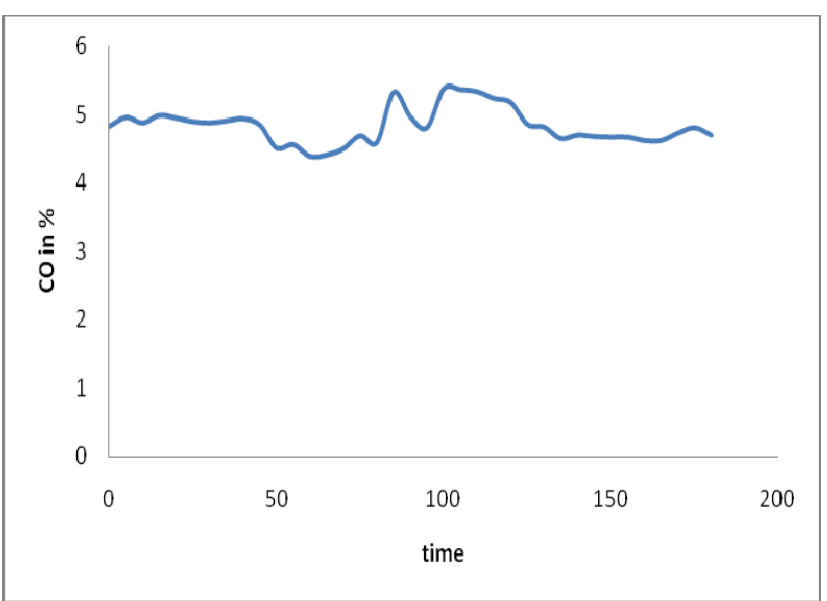

Fig 3 Showing the CO constituent without the device

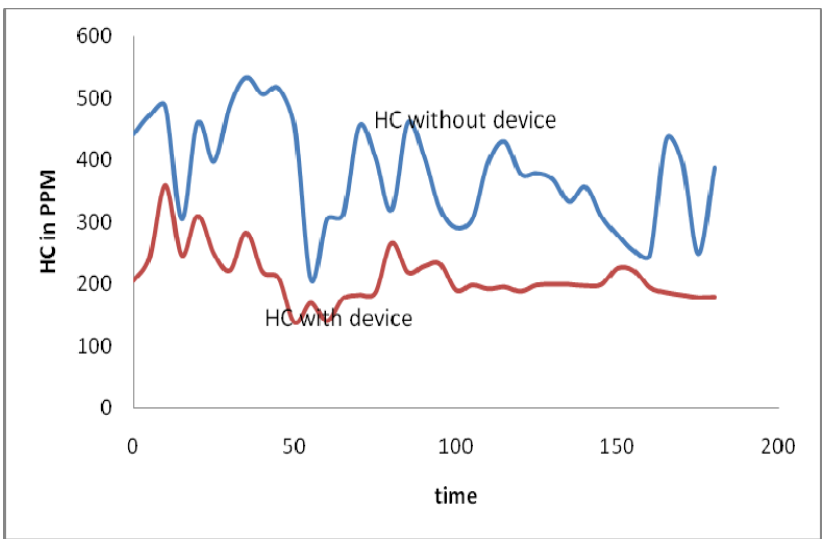

Fig 4 comparison of $\mathrm{HC}$ with and without device

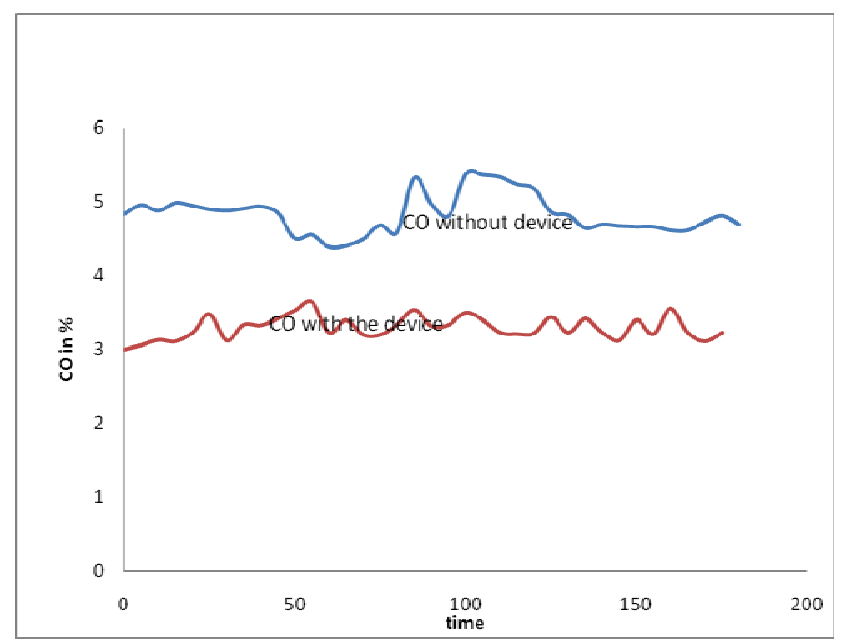

Fig 5 showing the comparison between $\mathrm{CO}$ with and without the device 


\section{CONCLUSION:}

This present work has shown that complete combustion of fuel may be obtained using a magnetic field around the fuel line of an internal combustion engine. It is scientific way of reducing fuel intake in an engine design project, making it fuel economy and reducing the rate of gas emission to the environment from engine combustion. The result from the experiment described in this paper, shows that the fuel consumption of the engine used for the same period are not the same. At the end of the three hours that this experiment lasted, the amount of fuel remaining in the tank were not the same though they were at the beginning. This paper concludes by suggesting that both the inlet manifold and the top cylinder be made of magnetic material in future engine design projects.

\section{REFERENCES}

[1]. Mundimex. Inc , Hydrocarbon Fuel Research Div \& Publish USA 1997;http://www. undi.com

[2]. Ki Hoon Song, Pratyush Nag, LitzingerA T and Daniel C, Effects of oxygenated additives on aromatic species in fuel rich, premixed ethane combustion, Combustion and Flame, Volume 135, Issue 3, November 2003, Pages 341-349

[3]. Okoronkwo C. A ,Okoro ,D , Osuala ,P(2007) The Effect Of Electromagnetic Field On Combustion Of Fuel ( Final Year Project Work Mechanical Engineering Department Federal University Of Technology, Owerri ,Nigeria)

[4] United States Environmental Protection Agency, Methodology for Estimating Emissions of $\mathrm{CH} 4, \mathrm{~N} 2 \mathrm{O}$, and Criteria Pollutants from Mobile Combustion, Annex E, 2001

[5] Nelson Saksono (2005) Magnetizing Kerosene For Increasing Combustion Efficiency JURNAL TEKNOLOGI, Edisi No. 2, Tahun XIX, Juni 2005, 155162 ISSN 0215-1685

[6] (Save the World Air Inc., 2001) 